Efri Roziaty, Daniek Hayu, Nur Aini Dewi Setyowati. (2018). Aktivitas Antibakteri Ekstrak Metanol Buah Syzygium polyanthum terhadap Pertumbuhan Bakteri Escherchia coli. Vol. 4 (1) Pp. 69-77. Doi:

https://doi.org/10.23917/bioeksperimen.v4i1.5689

\title{
Keragaman Plankton di Wilayah Perairan Waduk Cengklik Boyolali Jawa Tengah
}

\author{
Efri Roziaty*, Daniek Hayu, Nur Aini Dewi Setyowati \\ Program Studi Pendidikan Biologi \\ Fakultas Keguruan dan Ilmu Pendidikan Universitas Muhammadiyah Surakarta \\ *Email: er375@ums.ac.id
}

\begin{abstract}
Abstrak
Penelitian mengenai keragaman plankton di wilayah perairan Waduk Cenglik Boyolali masih sangat sedikit. Penelitian bertujuan untuk: mengidentifikasi keragaman jenis plankton yang berada di wilayah perairan Waduk Cengklik Boyolali. Metode pengambilan sampel dilakukan secara purpossive random sampling yaitu metode pengambilan sampel secara acak berdasarkan tujuan tertentu yang ditargetkan dalam penelitian. Pengambilan sampel akan dilakulan di bagian tepi waduk utama dekat pintu masuk waduk dan lokasi berikutnya adalah di bagian tengah waduk dengan menggunakan perahu. Pengambilan sampel dilakukan pada pagi dan sore hari dengan harapan menemukan plankton yang terkategori fitoplankton dan zooplankton. Sampel plankton kemudian diidentifikasi di laboratorium Pendidikan Biologi FKIP UMS. Hasil yang didapatkan berupa jenis-jenis plankton yang terdiri dari fitoplankton yang merupakan produsen di perairan dan zooplankton yang merupakan konsumen I di perairan. Indeks keanekaragaman zooplankton di Waduk Cengklik Boyolali didominasi oleh phylum Rotifera dan disusul oleh phylum Sarcomastigophora yang berkisar antara $-3,30$ sampai $-3,35$, sedangkan indeks keanekaragaman fitoplankton didominasi oleh divisi Bacillariophyta yang berkisar antara -2,43 sampai -3,08 yang menunjukkan bahwa komunitas biota tidak stabil disebabkan karena kualitas air tercemar berat. Kuantitasi dan jenis plankton yang ada mengindikasikan kualitas perairan tersebut.
\end{abstract}

Kata Kunci: plankton, Waduk Cengklik, bioindikator, fitoplankton, zooplankton

\section{Pendahuluan}

Waduk merupakan waduk alam atau waduk buatan, kolam penyimpan atau pembendungan sungai yang bertujuan untuk menyimpan air. Waduk dapat dibangun di lembah sungai pada saat pembangunan sebuah bendungan atau penggalian tanah atau teknik konstruksi konvensional seperti pembuatan tembok atau menuang beton. Salah satu waduk yang terletak di kawasan Solo Raya adalah Waduk Cengklik.

Kondisi geografi Waduk Cengklik terletak di Desa Ngargorejo, Kecamatan Ngemplak, Kabupaten Boyolali. Sejarah pembangunan waduk Cengklik pada tahun 1926-1928 oleh Pemerintah Belanda. Nama Cengklik diambil dari dukuh pertama yang dimulai menjadi waduk yaitu Dukuh Cengklik. Waduk ini terletak di Desa Ngargorejo dan Sobokerto, Kecamatan Ngemplak \pm 20 km, ke arah timur laut Kota Boyolali, Bila dari Bandara Adi Sumarmo $\pm 1,5 \mathrm{~km}$ (di sebelah barat bandara). Waduk dengan luas genangan 300 ha ini dibangun pada zaman Belanda, tujuannya untuk mengairi lahan sawah seluas 1.578 ha.

Letak Waduk Cengklik sangat strategis, berdekatan dengan Bandara Adi Sumarmo, Asrama Haji Donohudan, Monumen POPDA, dan Lapangan Golf. Sehingga selain dimanfaatkan sebagai sarana irigasi, Waduk Cengklik juga dimanfaatkan untuk perikanan dan destinasi wisata air di kabupaten Boyolali.

Kondisi fisika dan kimia perairan Waduk Cengklik berada di Wilayah Boyolali dengan kedalaman sekitar $0.5-2.5 \mathrm{~m}$. Suhu perairan berada di kisaran $27-31.5^{\circ} \mathrm{C}$. Tingkat kejernihan/ transparansi air sekitar $1.2-1.45 \mathrm{~m}$. Biological Oxygen Demand (BOD) yaitu berkisar antara 1.22.6. $\mathrm{pH}$ air berada di kisaran 5.7-10.5 (Pitoyo \& Wiryanto, 2001).

Sejauh ini pemanfaatan waduk adalah sebagai: 1) kontrol sumber air dan banjir. Waduk digunakan sebagai pengendali banjir khusus untuk wilayah permukiman sekitar terutama pada saat curah hujan tinggi. 2) sarana irigasi bagi pertanian sekitar 
waduk. Waduk Cengklik memiliki pintu air yang digunakan sebagai pengendali masuknya air ke sistem pertanian masyarakat sekitar. Walaupun demikian fungsi irigasi ini belum digunakan secara maksimal oleh warga terutama para petani yang masih menggunakan sistem pertanian tradisional tadah hujan. Areal pertanian yang mengandalkan irigasi dari Waduk Cengklik adalah seluas 1957 hektar, yang terdiri dari areal pertanian padi dan palawija. Selama ini, air Waduk Cengklik digunakan di 3 kecamatan, Kecamatan Ngemplak terdapat dua belas desa, Kecamatan Nogosari sebanyak lima desa, dan kecamatan Colomadu Karanganyar; 3) budidaya perikanan yaitu ikan tangkap dan keramba. Banyak sekali keramba yang ditanam di waduk (Gambar 1) bisa dilihat dari pencitraan satelit. Umumnya yang dipelihara adalah jenis ikan nila terutama ikan nila merah (Oreochromis nilotic).

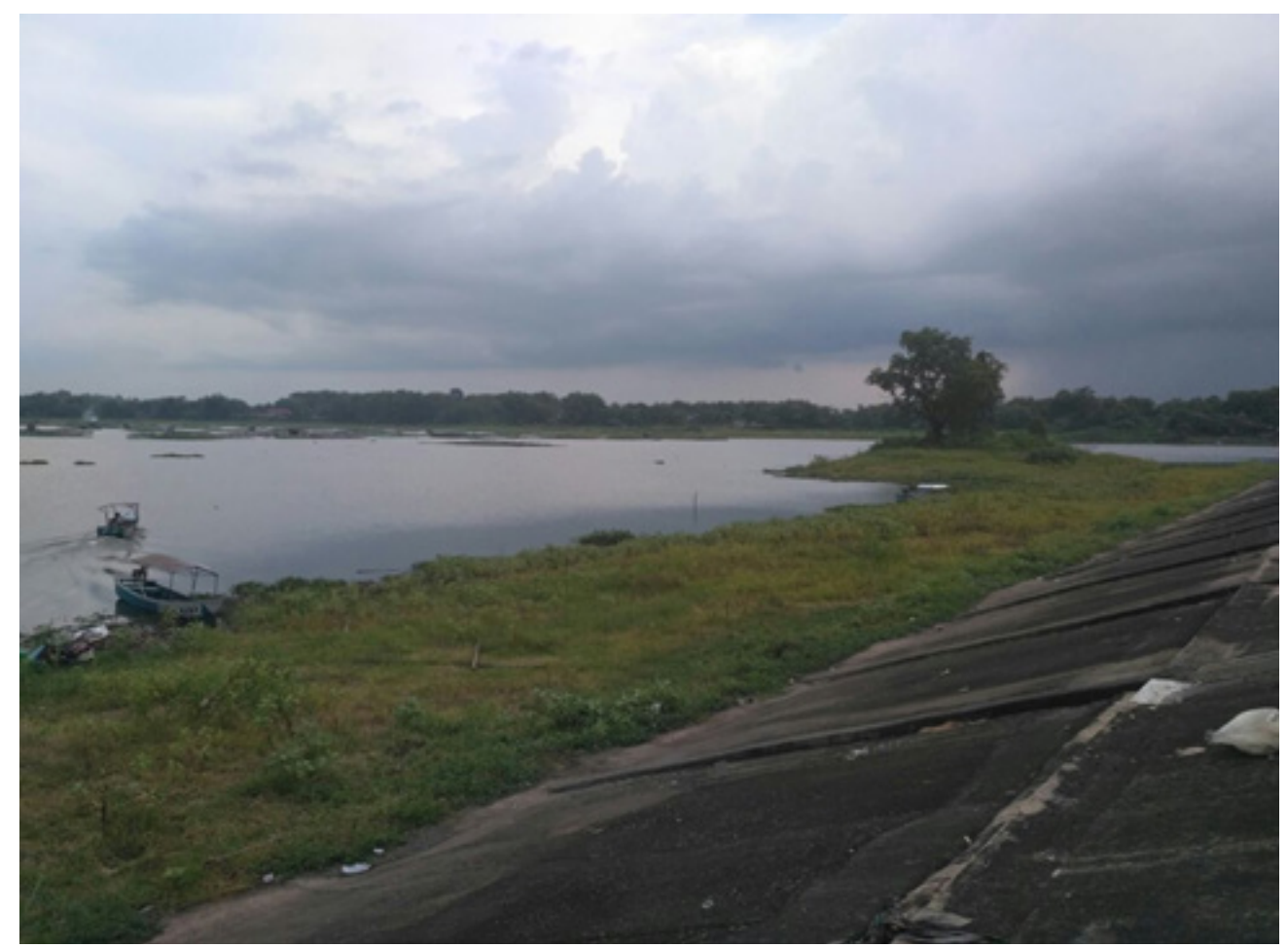

Gambar 1 Lokasi Waduk Cengklik (Dok. Pribadi)

Selain budi daya dengan keramba yang umumnya adalah ikan nila merah, ada juga pemanfaatan dengan menggunakan sistem tradisional ikan tangkap melalui jaring dan memancing. Beberapa jenis ikan yang bisa ditemui di Waduk Cengklik adalah jenis ikan sepat (Trichogaster trichopterus) ikan koi, ikan tombro, dan ikan wader (Barbus binotatus). Ikan sepat dan ikan wader diperoleh sebagai hasil samping bagi petani keramba dan warga sekitar Waduk Cengklik. Ikan sepat merupakan ikan yang cepat berkembang biak, ikan ini biasanya hidup berdampingan dengan ikan nila. Sedangkan ikan wader diperoleh oleh petani dan warga sekitar waduk dengan menggunakan jaring. Ikan wader ini merupakan menu yang tak boleh dilupakan bagi para pengunjung Waduk Cengklik dan merupakan menu khas dari pedagang makanan di sekitar tempat wisata Waduk Cengklik; 4) sarana pariwisata/rekreasi yang biasa terdapat di sekitar waduk biasanya adalah dengan mengendarai perahu berkeliling waduk (Gambar 2). 


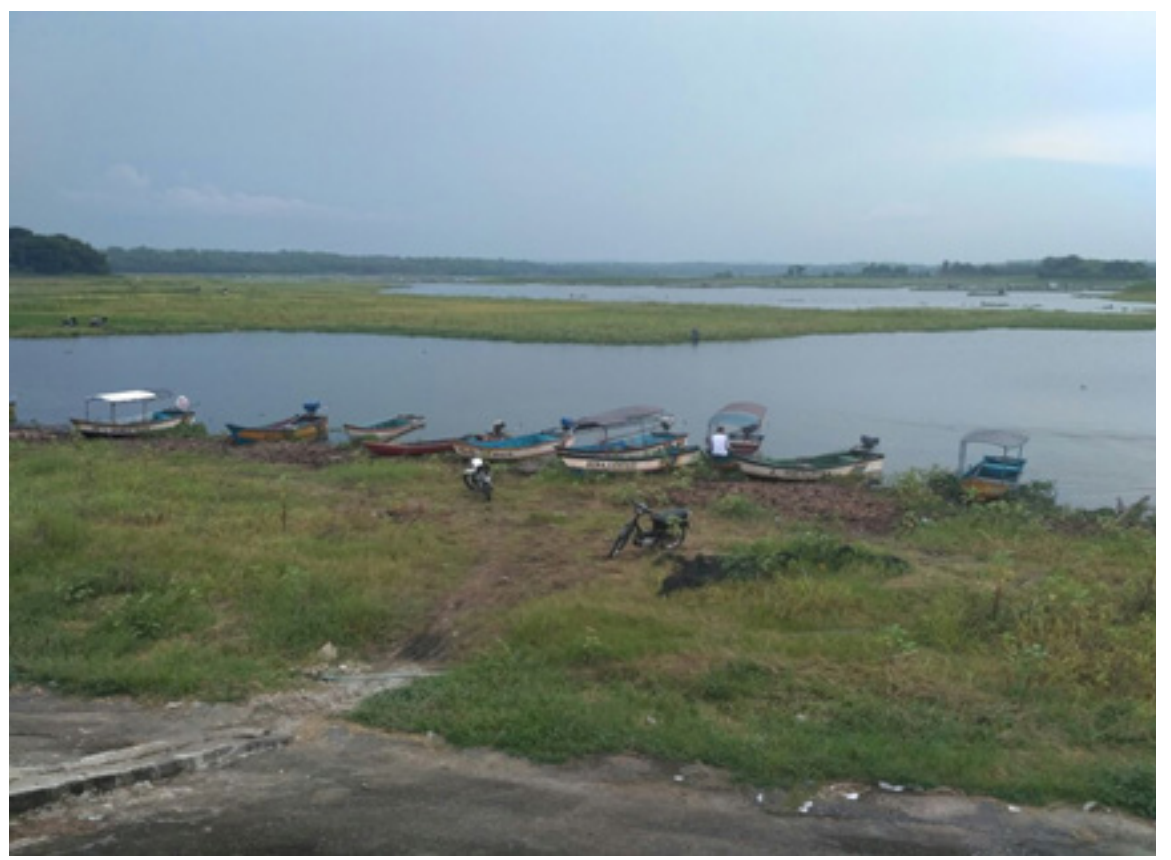

Gambar 2 Sektor pariwisata yaitu perahu yang digunakan untuk mengantar wisatawan berkeliling waduk (Dok. Pribadi)

Plankton merupakan organisme yang berukuran miron yang hidup melayang-layang di permukaan air. Gerakannya sangat dipengaruhi oleh arus air dikarenakan ukuran dan bobot plankton yang sangat kecil. Plankton dibagi menjadi dua golongan besar, yaitu fitoplankton dan zooplankton. Fitoplankton membawa karakteristik tumbuhan sehingga organisme ini berperan sebagai produsen di wilayah perairan. Sedangkan zooplankton adalah pemakan fitoplankton. Zooplankton merupakan konsumen tingkat I di wilayah perairan. Zooplankton membawa karakteristik hewan. Adanya plankton di suatu perairan dapat mengindikasikan kualitas suatu perairan. Secara kuantitatif dan kualitatif plankton dapat digunakan untuk menentukan tingkat kesuburan suatu perairan (Susanti, 2010).

Selain itu, penelitian mengenai eutrofikasi atau tingkat kesuburan suatu perairan telah dilakukan oleh para peneliti dengan menggunakan bioindikator plankton (Yazwar, 2008). Penelitian lain yang dilakukan di wilayah perairan Waduk Cengklik menganalisis produktivitas primer perairan di mana produktivitas primer kotor permukaan perairan Waduk Cengklik Boyolali Jawa Tengah tergolong tinggi berkisar antara 11.122.50022.545.600 $\mathrm{mgC} / \mathrm{m} 3 /$ hari. Produktivitas primer kotor yang tinggi terutama dipengaruhi oleh cahaya, konsentrasi nutrien, serta kepadatan klorofil fitoplankton dan makrofita (Pitoyo \& Wiryanto, 2001).

Penelitian ini bertujuan untuk mengidentifikasi keragaman jenis plankton yang berada di wilayah perairan Waduk Cengklik Boyolali. Dengan mengetahui keragaman jenis plankton yang ada di Waduk Cengklik diasumsikan bahwa dapat diperkirakan kualitas perairan wilayah tersebut.

\section{Metode Penelitian}

\section{Lokasi dan waktu pengamatan}

Penelitian dilakukan di Waduk Cengklik Boyolali Jawa Tengah. Waktu penelitian dilakukan pada Bulan Januari-September 2017 di pagi hari sekitar pukul 6.00 dan sore hari sekitar pukul 18.00.

\section{Bahan dan alat}

Alat yang digunakan selama pengamatan adalah tallysheet, alat tulis, kamera, botol flakon, sprayer, plastik/boks spesimen, kertas label, plankton net, mikroskop, dan sedwidge rafter. Bahan yang digunakan adalah plankton dan alkohol $70 \%$.

\section{Metode dan pengambilan sampel}

Metode yang digunakan adalah purpossive random sampling. Pengambilan sampel disesuaikan dengan tujuan penelitian. Lokasi penelitian di wilayah perairan Waduk Cengklik Boyolali Jawa 
Tengah. Stasiun A terletak di bagian tepi waduk dekat jalan masuk waduk sebagai dan Stasiun B yang terletak di bagian tengah waduk (Fachrul, 2007).

Masing-masing stasiun akan dibagi menjadi 3 sub stasiun di tempat yang telah dipilih/ditentukan. Selanjutnya pada masing-masing sub stasiun dilakukan pengambilan sampel plankton dengan ulangan sebanyak dua kali.

Untuk teknis pengambilan sampel plankton adalah dengan cara menggunakan ember plastik volume $250 \mathrm{ml} / 2,5$ liter. Atau setara dengan penyaringan air sebanyak 10 liter dari lokasi sampling dengan menggunakan ember ukuran 2,5 liter dan dilakukan sebanyak 4 kali penyaringan. Menyaring air yang terkumpul dengan plankton-net di mana jaring plankton tersebut telah dilengkapi dengan tabung pengumpul plankton berukuran $5 \mathrm{ml}$. Memindahkan sampel yang diperoleh ke dalam botol sampel (flakon) dengan volume $5 \mathrm{ml}$ kemudian memberi alkohol $70 \%$ sebanyak 3-5 tetes, jika langsung diamati sebaiknya tidak perlu diberi alkohol 70\% dan memberikan label.

Untuk identifikasi lebih lanjut sampel dibawa ke laboratorium Prodi Pendidikan Biologi FKIP UMS. Identifikasi menggunakan buku (Redden, Kobayashi, Iain Suthers, Rissik, \& Newton, 2009); (Nontji, 2005) dan (Romimohtarto \& Juwana, 2005). Identifikasi dilakukan dengan menggunakan tangkapan foto plankton yang didapat melalui perbesaran mikroskop dan ditayangkan dengan obtilab kemudian dibandingkan dengan beberapa sketsa/gambar yang terdapat dalam buku penuntun identifikasi. Selain itu, beberapa informasi terkait dengan plankton di situs internet salah satunya adalah http://ewinasis.blogspot.co.id/2012/08/ identifikasi-plankton.html?m=1.

\section{Analisis Data}

Data yang diambil adalah jenis plankton, kemelimpahan plankton dan distribusi plankton. Indeks keragaman menggunakan Indeks ShannonWienner. Data dengan menggunakan buku panduan identifikasi. Buku panduan identifikasi plankton menggunakan Buku Plankton-A guide to their ecology and monitoring for water quality (Editor: Iain M. Suthers dan David Rissik). Sedangkan Indeks Kesamaan menggunakan Indeks Similaritas dari Sorensen.

Analisis faktor abiotik perairan seperti suhu dan $\mathrm{pH}$ akan dilakukan di lapangan. Untuk datadata lain sepertii DO, BOD, dan COD serta logam akan menggunakan data sekunder.

\section{Hasil dan Pembahasan}

1. Kondisi Waduk Cengklik Boyolali

Hasil pengukuran terhadap factor-faktor abiotik Waduk Cengklik Boyolali terlihat pada di bawah ini (Tabel 1).

Tabel 1 Kondisi Waduk Cengklik Boyolali tahun 2017.

\begin{tabular}{clcccc}
\hline No & \multicolumn{1}{c}{$\begin{array}{c}\text { Parameter } \\
\text { Primer }\end{array}$} & Stasiun A & Stasiun B & Kisaran & Ket \\
\hline 1 & Kelembapan udara (\%) & $69-73$ & $75-78$ & $60-90$ & Normal \\
2 & Suhu udara () & $24,9-26,4$ & $26,3-27,3$ & $15-30$ & Normal \\
3 & Suhu air () & $2,7-2,8$ & $2,7-2,8$ & $2,1-3,5$ & Normal \\
4 & $\mathrm{pH}$ & 7 & 7 & $6-8$ & Normal \\
5 & $\mathrm{DO}(\mathrm{ppm})^{*}$ & 6,53 & 5,13 & $4-9$ & Normal \\
6 & BOD $(\mathrm{mg} / \mathrm{L})^{* *}$ & 1,2 & 1,3 & $0-10$ & Normal \\
\hline
\end{tabular}

Kelembapan udara (\%) menyatakan banyaknya uap air dalam udara. Kelembapan udara akan berbanding terbalik dengan suhu udara di suatu daerah. Jika suhu udara tinggi maka kelembaban akan lebih rendah. Hal tersebut sesuai dengan pengamatan yang dilakukan di Waduk
Cengklik Boyolali. Kelembapan udara pada stasiun B lebih tinggi dibandingkan dengan stasiun A (Tabel 1), hal ini terjadi karena pada stasiun B bagian hulu adanya aktivitas penambakan ikan, banyak eceng gondok di dekat penambakan dan terdapat pulau kecil yang dipenuhi pohon-pohon 
besar yang tidak begitu mempengaruhi kenaikan suhu udara. Kisaran normal kelembapan udara adalah 60\%-90\%, sehingga pada Waduk Cengklik masih dikatakan normal atau tidak mempengaruhi aktivitas plankton di Waduk Cengklik Boyolali. Kelembaban yang tinggi akan mempengaruhi peningkatan produktivitas mikroorganisme di dalam perairan (Jordan, 1995).

Suhu udara $\left({ }^{\circ} \mathrm{C}\right)$ diukur menggunakan termohigrometer. Hasil pengukuran suhu udara stasiun B lebih tinggi dibandingkan dengan stasiun A, hal ini terjadi karena perbedaan aktivitas yang terjadi di masing-masing stasiun. Hasil pengukuran suhu udara pada stasiun A dan B berkisar antara 24,9-27,3 ${ }^{\circ} \mathrm{C}$ (Tabel 4.1). Hasil tersebut termasuk angka kisaran normal bagi pertumbuhan dan perkembangan plankton dalam perairan air tawar, di mana kisaran normal yaitu 20-30 ${ }^{\circ} \mathrm{C}$ (Effendi, 2000). Suhu sangat berpengaruh bagi keberadaan organisme, hal ini disebabkan suhu merupakan faktor pembatas utama, karena organisme akuatik sering mempunyai toleransi yang sempit. Perubahan suhu menyebabkan pola sirkulasi yang khas yang dapat mempengaruhi kehidupan organisme akuatik (Odum, 1993).

Menurut Basmi (1999) menyatakan bahwa dalam setiap penelitian pada ekosistem akuatik pengukuran suhu air adalah hal yang mutlak untuk dilakukan. Hal ini disebabkan kelarutan berbagai gas di air serta semua aktivitas biologis di dalam ekosistem akuatik sangat dipengaruhi oleh suhu. Suhu air dipengaruhi oleh suhu udara di sekitarnya dan intensitas cahaya yang masuk ke badan perairan. Hasil pengukuran di stasiun A dan stasiun B menunjukkan angka berkisar 2,72,8 (Tabel 1). Nilai tersebut merupakan nilai yang normal bagi perkembangan plankton di perairan tropis yaitu 21-35 (Wardoyo, 1983). Menurut Barus (2004) terdapat beberapa faktor yang mempengaruhi temperatur perairan di antaranya intensitas cahaya, pertukaran panas antara udara dengan air sekelilingnya dan banyaknya kanopi di daerah tersebut.

Pengamatan $\mathrm{pH}$ air yang telah diamati menggunakan $\mathrm{pH}$ indikator. Besaran $\mathrm{pH}$ yang diukur memiliki pH 7 pada dua stasiun (Tabel 1). Angka tersebut merupakan angka yang normal untuk besar $\mathrm{pH}$ perairan. Menurut Kristanto (2002), pH air yang normal adalah sekitar 6-8, sedangkan untuk air yang tercemar akan memiliki $\mathrm{pH}$ yang lebih rendah atau lebih tinggi sesuai dengan tingkat pencemarnya.

Pengukuran parameter DO pada Waduk Cengklik pada stasiun A sebesar 6,53 dan stasiun B sebesar 5,13 (Tabel 1). Hasil uji DO menunjukkan bahwa kualitas air di Waduk Cengklik masih tergolong normal, di mana kisaran normal DO perairan yaitu 4-9 ppm (Odum, 1993). Parameter BOD, terlihat bahwa pada Waduk Cengklik memiliki kandungan kimia BOD stasiun A 1,2 $\mathrm{mg} / \mathrm{L}$ dan stasiun B $1,3 \mathrm{mg} / \mathrm{L}$ (Tabel 1). Hasil uji BOD menunjukkan bahwa kualitas air di Waduk Cengklik tergolong tercemar rendah. Kualitas air dikatakan tercemar rendah jika hasil uji yang diperoleh rendah dengan interval 0-10 $\mathrm{mg} / \mathrm{L}$ (Heriyanto, 2012). BOD menunjukkan banyaknya oksigen yang dikonsumsi oleh mikroba aerob dalam pross respirasi (Boyd, 1988). BOD hanya menggambarkan bahan organik yang dapat didekomposisi secara biologis. Selain itu limbah domestik maupun industri dapat mempengaruhi nilai BOD (Effendi, 2003). BOD dalam suatu perairan dapat digunakan sebagi petunjuk terjadinya pencemaran (Lee, 1978).

\section{Identifikasi dan Perhitungan Plankton}

Keanekaragaman zooplankton di Waduk Cengklik ditemukan ada 31 spesies, 15 genus, dan 14 familia dari 5 phylum utama, phylum yang memiliki keanekaragaman spesies terbanyak yang ditemukan adalah Rotifera meliputi 13 spesies dari 6 genus (Tabel 3). (Asplanchna sp., Trichocerca sp., Rotaria sp., Conochilus sp., Lepadella sp., Branchionus sp.). Penelitian ini sesuai dengan penelitian (Handayani \& Patria, 2005) tentang zooplankton di Waduk Krenceng Cilegon yang menunjukkan hasil bahwa spesies dalam anggota Rotifera paling banyak ditemukan. Rotifera menjadi Phylum yang paling banyak ditemukan di ketiga stasiun penelitian karena Rotifera memiliki pergerakan yang lambat dan sering dimanfaatkan sebagai pakan ikan. 
Tabel 2 Keanekaragaman fitoplankton di Waduk Cengklik tahun 2017

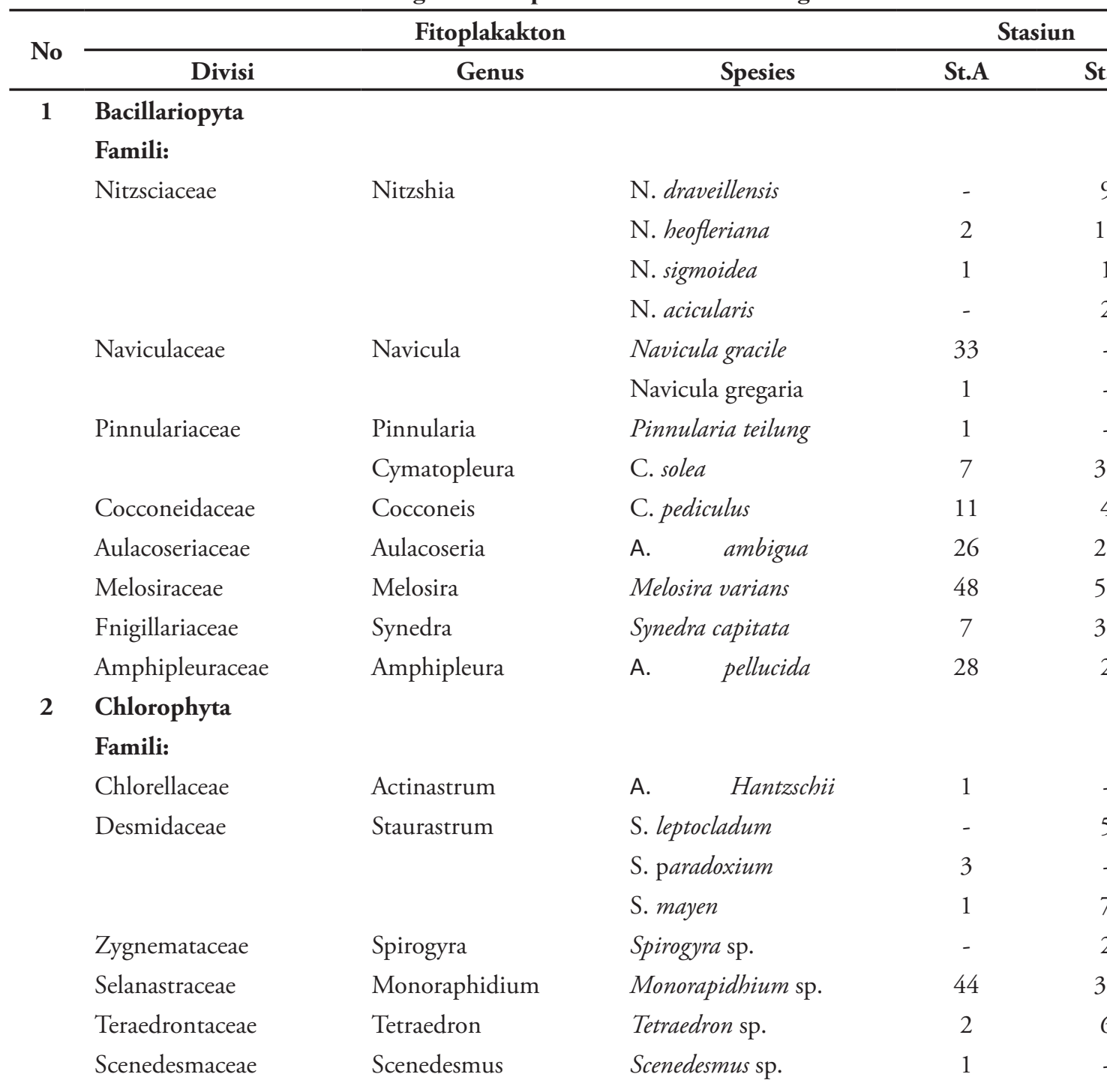

\section{Cyanophyta}

Famili:

Oscillatoriacea

Anthospira

A. platensis

5

Oscillaria

O. limosa

9

Nostocaceae

Cylindrispermopsis

C. vacibarskii

Merismopediaceae

Merismopedia

Merismopedia sp.

42

9

t.B

4 Chrysophyta

Famili:

Synuraceae

Synura

Synura uvella

5

5 Euglenophyta

Famili:

Euglenaceae

Euglena

Euglena mutabilis

4 4 
Tabel 3 Keanekaragaman zooplankton di Waduk Cengklik tahun 2017

\begin{tabular}{|c|c|c|c|c|c|c|}
\hline \multirow{2}{*}{ No } & \multicolumn{3}{|c|}{ Zooplankton } & \multicolumn{3}{|c|}{ Stasiun } \\
\hline & Phylum & Genus & Spesies & SA & SB & $\mathrm{Jml}$ \\
\hline \multirow[t]{15}{*}{1} & Rotifera * & & & & & \\
\hline & Familia & & & & & \\
\hline & Asplanchnidae & Asplanchna & A. brigthwelli & 7 & 4 & 11 \\
\hline & & & A. herricki & 8 & 3 & 11 \\
\hline & & & A.girodi & 6 & 3 & 9 \\
\hline & Trichocercidae & Trichocerca & T. pusilla & 9 & 7 & 16 \\
\hline & & & T. similis similis & 8 & 8 & 16 \\
\hline & & & T. weberi & 6 & 9 & 15 \\
\hline & Philodinidae & Conochilus & C. hippocrepis & 2 & 4 & 6 \\
\hline & & Rotaria & R. citrina & 3 & 2 & 5 \\
\hline & Brachionidae & Lepadella & Lepadella patella & 4 & 3 & 7 \\
\hline & & Branchionus & B. calyciflorus & 7 & 8 & 15 \\
\hline & & & B. caudatus & 5 & 3 & 8 \\
\hline & & & B. urceolaris & 4 & 6 & 10 \\
\hline & & & Keratella tropica & 3 & 2 & 5 \\
\hline \multirow[t]{12}{*}{2} & Sarcomastigophora & & & & & \\
\hline & Familia & & & & & \\
\hline & Arcellidae & Arcella & Arcella gibbosa & 9 & 11 & 20 \\
\hline & & & Arcella vulgaris & 12 & 9 & 21 \\
\hline & & & A. crenulata & 10 & 8 & 18 \\
\hline & & & A.discoides & 8 & 8 & 16 \\
\hline & & & A. hemisphaerica & 7 & 6 & 13 \\
\hline & & & A.dentata & 6 & 11 & 17 \\
\hline & Difflugiidae & Difflugia & Difflugia varians & 9 & 9 & 18 \\
\hline & & & Difflugia gramen & 6 & 7 & 13 \\
\hline & & & D. lobostoma & 7 & 5 & 12 \\
\hline & & & D. acuminata & 8 & 9 & 17 \\
\hline \multirow[t]{6}{*}{3} & Chiliophora & & & & & \\
\hline & Familia & & & & & \\
\hline & Vorticellidae & Vorticella & V. campanula & 3 & 2 & 5 \\
\hline & Parameciidae & Paramaecium & P. bursaria & 4 & 3 & 7 \\
\hline & Tetrahymenidae & Colpidium & C. colpoda & 4 & 5 & 9 \\
\hline & Didiniidae & Didinium & D. chlrorelligerum & 3 & 2 & 5 \\
\hline \multirow[t]{3}{*}{4} & Protozoa ** & & & & & \\
\hline & Familia & & & & & \\
\hline & Peranemataceae & Heteronema & H. exaratum & 5 & 9 & 14 \\
\hline \multirow[t]{3}{*}{5} & Arthropoda & & & & & \\
\hline & Familia & & & & & \\
\hline & Sididae & Diaphanosoma & D. birgei & 4 & 2 & 6 \\
\hline
\end{tabular}




\begin{tabular}{|c|c|c|c|c|c|c|}
\hline \multirow{2}{*}{ No } & \multicolumn{3}{|c|}{ Zooplankton } & \multicolumn{3}{|c|}{ Stasiun } \\
\hline & Phylum & Genus & Spesies & SA & SB & Jml \\
\hline & & & D. sarsi & 5 & 4 & 9 \\
\hline & Cypridoidea & Stenocypris & S.hirutai & 6 & 6 & 12 \\
\hline \multicolumn{4}{|c|}{ Jumlah Individu Zooplankton } & 188 & 178 & \\
\hline \multicolumn{4}{|c|}{ Total } & \multicolumn{3}{|c|}{366} \\
\hline
\end{tabular}

\section{Identifikasi dan Perhitungan Plankton}

Kepadatan jumlah fitoplankton tertinggi berada di stasiun A yang berada di bagian tepi Waduk Cengklik dengan jumlah fitoplankton 263 individu, di mana lokasi tersebut terletak di daerah permukiman, area pemancingan, dan dekat dengan pembuangan sampah. Sedangkan pada stasiun B kepadatan fitoplankton berjumlah 207 individu, di mana lokasi tersebut terletak di daerah pertambakan, area pemancingan, limbah transportasi perahu nelayan. (Tabel 2). Kepadatan zooplankton di stasiun A daerah tepi dekat pintu masuk lebih tinggi yaitu 188 individu, dibandingkan dengan di stasiun $\mathrm{B}$, yaitu daerah tengah 178 individu. (Tabel 3).

Zooplankton di perairan yang mengalir (lotik) akan lebih sedikit jika dibandingkan dengan kepadatan zooplankton di perairan yang tenang (lentik). Hal ini berhubungan dengan kecepatan arus perairan di mana zooplankton akan lebih mudah ditemukan di perairan yang tenang dengan tingkat kejernihan yang tinggi. Sehingga dapat dikatakan bahwa kepadatan individu di stasiun A dan B termasuk tinggi atau banyak karena perairan termasuk tenang (lentik) (Barus, 2004).

Hasil identifikasi fitoplankton Waduk Cengklik stasiun A dan B ditemukan 27 spesies dari 21 genus dan 5 divisi utama, yaitu Bacillariophyta (9 genus, 13 spesies), Chlorophyta (6 genus, 8 spesies), Chyanophyta (4 genus, 4 spesies), Chrysophyta (1 genus, 1 spesies), dan Euglenophyta (1 genus, 1 spesies). Berdasarkan hasil yang diperoleh, variasi genus yang banyak ditemuakan adalah dari divisi Bacillariophyta. Hal ini sesuai dengan penelitian yang dilakukan oleh Menur, Siti, \& Mustofa (2014), pada Sungai Bremi ditemukan fitoplankton dengan genus yang banyak ditemukan dari Kelas Bacillariophyceae (12 spesies), Kelas Dinophyceae
(3 spesies), dan Kelas Cyanophyceae (1 spesies) (Tabel 2).

Berdasarkan persentase jumlah divisi fitoplankton, pada stasiun A persentase jumlah tertinggi adalah Divisi Bacillariophyta dengan jumlah individu sebesar $62,73 \% \%$ dan terendah adalah Divisi Euglenophyta dengan jumlah individu $1,52 \%$. Stasiun B persentase jumlah tertinggi adalah Divisi Bacillariophyta dengan jumlah individu sebesar 89,85\% dan terendah adalah Divisi Euglenophyta dengan jumlah individu 1,93\%. Berdasarkan hasil persentase dapat dilihat bahwa persentase jumlah individu pada divisi fitoplankton yang ditemukan tertinggi di Waduk Cengklik adalah Divsi Bacillariphyta. Sejalan penelitian Maresi, Priyanti, \& Yunita (2015), bahwa kelas Bacillariopycecae kelimpahannya di perairan sangat tinggi, hal ini disebabkan adanya limbah organik dari daerah pertambakan dan permukiman penduduk merupakan penyediaan utama posfor dan nitrogen yang dibutuhkan oleh fitoplankton untuk pertumbuhnnya.

Persentase tertinggi adalah pada Phylum Sarcomastigophora $46,62 \%$ pada stasiun B dan 43,61\% pada stasiun A. hal ini dapat disimpulkan bahwa jumlah persentase tertinggi ialah pada Phylum Sarcomatigophora dan disusul oleh Phylum Rotifera. Phylum Sarcomastigophora menjadi phylum yang memiliki jumlah spesies terbanyak karena Phylum ini sangat mudah beradaptasi di lingkungan perairan walaupun tercemar. Menurut Suther \& Rissik, (2008) zooplankton dapat dijadikan indikator perairan tercemar khususnya di air tawar. Semakin banyak spesies pada phylum ini maka menandakan kualitas air semakin rendah dikarenakan air yang kotor adalah habitat dari sebagian anggota phylum ini. 
Tabel 4 Perhitungan indeks keanekaragaman plankton di Waduk Cengklik

\begin{tabular}{ccccc}
\hline No & & Stasiun & Zooplankton & Fitoplankton \\
\hline 1 & Stasiun A & $-3,35$ & $-2,43$ \\
2 & Stasiun B & $-3,30$ & $-3,08$ \\
\hline
\end{tabular}

Hasil perhitungan indeks keanekaragaman fitoplankton di Waduk Cengklik terlihat bahwa indeks keanekaragaman fitoplankton pada stasiun A -2,43 dan stasiun B yaitu -3,08, sedangkan pada indeks keanekaragaman zooplankton stasiun A yaitu $-3,35$ dan stasiun B yaitu -3,30 (Tabel 4). Hasil dari perhitungan indeks keanekaragaman stasiun A dan stasiun B tersebut, maka dapat diketahui bahwa keanekaragaman plankton perairan menunjukkan $\mathrm{H}^{\prime}<1$. Menurut persamaan Shanoon-Wiener jika $H^{\prime}<1$ berarti kualitas biota tidak stabil atau kualitas air tercemar berat (Fachrul, 2007). Sejalan dengan penelitian Soegiyanto (2009), indeks keanekaragaman dengan persamaan Shannon-
Wiener dikatakan buruk jika hasil yang diperoleh berkisar antara $<0$.

\section{Simpulan}

Indeks keanekaragaman zooplankton di Waduk Cengklik Boyolali didominasi oleh phylum Rotiferadan disusul oleh phylumSarcomastigophora yang berkisar antara -3,30 sampai -3,35, sedangkan indeks keanekaragaman fitoplankton didominasi oleh divisi Bacillariophyta yang berkisar antara $-2,43$ sampai -3,08 yang menunjukkan bahwa komunitas biota tidak stabil disebabkan karena kualitas air tercemar berat.

\section{Daftar Pustaka}

Barus, T. (2004). Pengantar Limnologi Studi tentang Ekosistem Air Daratan. Medan: USU press.

Basmi, J. (1999). Planktonologi: Biokologi Plankton Algae. Bogor: Fakultas Perikanan dan Ilmu Kelautan IPB.

Fachrul, M. F. (2007). Metode Sampling Bioteknologi. Jakarta: Bumi Aksara.

Handayani, S., Patria, Mufti. P. (2005). Komunitas Zooplankton di Perairan Waduk Krenceng, Cilegon, Banten. Makra, Sains, 9(2), 75 - 80.

Kristanto, P. (2002). Ekologi Industri. Yogyakarta: Penerbit ANDI.

Odum, E. P. (1993). Fundamental of Ecolog Third Edition. Philadelphia: W. B. Sounder CO.

Pitoyo, A., \& Wiryanto. (2001). Produktivitas Primer Perairan Waduk Cengklik Boyolali. Biodiversitas, 189-195.

Redden, A. M., Kobayashi, T., Iain Suthers, L. B., Rissik, D., \& Newton, G. (2009). Plankton Process and The Environment. In I. Suthers, \& D. Rissik, Plankton - A Guide to Their Ecology and Moniotring for Water Quality (pp. 15-38). Collingwood, Australia: CSIRO Publishing .

Reyden, A., Kobayashi, T., Suthers, I., Bowling, L., \& Newton, D. R. (2009). Plankton Process and the environment. In I. Suthers, \& D. Rissik, Plankton: A guide to their ecology and monitoring for water quality (pp. 15-38). Australia: Csiro Publishing .

Wardoyo, S. (1983). Metode Pengukuran Kualitas Air. Training: Penyusunan Analisis Mengenai Dampak Lingkungan. Bogor: Institut Pertanian Bogor. 